\title{
Identification and characterization of Moraxella phenylpyruvica
}

\author{
J. J. S. SNELL, L. R. HILL, AND S. P. LAPAGE \\ From the National Collection of Type Cultures, Central Public Health Laboratory, London
}

SYNOPSIS Eight strains of Moraxella phenylpyruvica have been isolated from clinical material in the United Kingdom, the first to be reported from this country. They were characterized, together with three strains of $M$. phenylpyruvica of the National Collection of Type Cultures (NCTC), and compared with NCTC strains of eight other Moraxella species. The strains of $M$. phenylpyruvica formed a homogeneous group which is readily distinguishable from other Moraxella species. Deamination of phenylalanine is not restricted to $M$. phenylpyruvica which, however, is urease positive and is stimulated by bile, in contrast to other Moraxella spp.

Flamm (1957) described a strain of Moraxella which he named $M$. polymorpha, isolated from the cerebrospinal fluid of a child with meningitis. Bøvre and Henriksen (1967) examined this strain and found it to agree in a number of characters with eight other Moraxella strains from such clinical sources as the urogenital tract, blood cultures, and pus. They considered that Flamm's strain belonged to the same species as the other eight strains and suggested that the epithet 'polymorpha' in Moraxella polymorpha was illegitimate and would cause confusion with De Bord's (1939, 1942) Mima polymorpha. The strains were found to deaminate phenylalanine, a property which was thought to be unusual in the genus Moraxella, and Bøvre and Henriksen proposed renaming this species $M$. phenylpyruvica (see also Judicial Commission of the International Committee on Systemic Bacteriology, 1971).

Eight strains of $M$. phenylpyruvica isolated in the UK from clinical material (urogenital tract, pleural Received for publication 17 August 1972. fluid, nasal swabs, and various lesions) have been examined in the National Collection of Type Cultures (NCTC), together with the three NCTC strains of this species. During a comparison of these strains with eight other Moraxella species, it was found that the ability to deaminate phenylalanine is not limited to $M$. phenylpyruvica (Snell and Davey, 1971). However, M. phenylpyruvica can be distinguished from other Moraxella species by several other characters as well as deamination of phenylalanine. The purpose of the present work is to record the isolation of this little-known organism in the UK, and to record a number of hitherto undescribed characteristics which help to distinguish it from other Moraxella species.

\section{Materials and Methods}

ORGANISMS

Eleven strains of $M$. phenylpyruvica were examined (Table I): eight field strains sent to the NCTC for

\begin{tabular}{llll}
\hline Strain No. & Original Strain Designation & Received from \\
\hline 1 & A152/68 & M. P. Jevons, London & Source \\
2 & A12/70 & R. F. Alexander, London & Vulva \\
3 & A30/70 & E. G. Gordon, Worcestershire & Urine \\
4 & A58/70 & E. G. Gordon, Worcestershire & Vagina \\
5 & A80/70 & J. C. Burne, Dartford & Nasal swab \\
6 & A81/70 & K. B. Rogers, Birmingham & Pressure sore \\
7 & A84/70 & W. E. Rimington, Doncaster & Lartholin cyst \\
8 & A100/71 & I. R. Poulter, Warwick & Blood \\
NCTC 10526 & 2863 & American Type Culture Collection, ATCC 23333 \\
NCTC 10750 & 5542 & American Type Culture Collection, ATCC 23334 \\
NCTC 10752 & - & American Type Culture Collection, ATCC 17958 \\
\hline
\end{tabular}

Table I Strains of Moraxella phenylpyruvica examined in the present work 
identification; three NCTC strains including the neotype of $M$. phenylpyruvica (NCTC 10526) and Flamm's strain of $M$. polymorpha (NCTC 10752). Strains of eight other Moraxella species were examined for comparison and are listed in Table II.

\begin{tabular}{ll}
\hline Name & Number \\
\hline$M$. bovis & NCTC 8561, 9425, 9426, A52/691 \\
$M$. kingii & NCTC 10526, 10746 \\
$M$. lacunata & NCTC 7985, 10747, 10748 \\
$M$. liquefaciens & NCTC 7911, 10358, 10359 \\
$M$. nonliquefaciens & NCTC 7784, 10464, A33/67, A9/69 \\
$M$. osloensis & NCTC 10465, 10749, 10755, 10756 \\
$M$. saccharolytica & \\
$M$. sp. $^{3}$ & NCTC 10753 \\
\hline
\end{tabular}

Table II Strains of other Moraxella spp. examined in the present work

${ }^{1}$ Strains with designations prefixed by $\mathbf{A}$ are field strains identified in the NCTC.

'Described by Flamm (1956).

${ }^{3}$ Described by van Bijsterveld (1970, 1971).

\section{CLINICAL DETAILS OF THE FIELD STRAINS}

\section{Strain 1}

A 4-year-old girl, admitted to hospital for investigation of enuresis, had a mild vulvo-vaginitis. The vaginitis cleared spontaneously.

\section{Strain 2}

A primigravida with preeclamptic toxaemia was found to have excess albumin in the urine. The strain was isolated on one occasion only and a normal delivery took place two weeks later.

\section{Strain 3}

This strain was isolated from pleural fluid of a $67-$ year-old man, admitted to hospital with diffuse pulmonary fibrosis.

\section{Strain 4}

This strain was present in large numbers in a vaginal discharge. The normal flora was very scanty.

\section{Strain 5}

A 14-month-old girl with gastroenteritis yielded this strain from a nasal swab. The gastroenteritis cleared up rapidly and spontaneously within two days.

\section{Strain 6}

An 11-year-old boy, born with a myelocoele and spina bifida, had both faecal and urinary incontinence. A pressure sore developed in which this strain was present in large numbers together with Proteus sp. and non-haemolytic and viridans type streptococci.

\section{Strain 7}

A 26-year-old woman had for three years a Bartholin cyst which became infected and from which this: strain was isolated. After excision of the cyst, sh $\overrightarrow{\vec{E}}$ fully recovered.

\section{Strain 8}

A man with a severe ankle injury developed a le $\frac{\overline{0}}{2}$ ulcer after seven weeks in plaster. The strain was isolated from the ulcer on two occasions before and? during treatment with first fucidin, then ampicillin, $\vec{\rho}$ and finally ultraviolet light.

\section{BACTERIOLOGICAL INVESTIGATIONS}

The media and methods used were mainly those described in Cowan and Steel (1965). The media were supplemented where indicated with horse blood or serum. The microscopic appearance was examinecis after 24 hours' growth at $37^{\circ} \mathrm{C}$ on $5 \%(\mathrm{v} / \mathrm{v})$ blood nutrient agar. Tests for motility were carried out by the hanging drop method from overnight cultures in $10 \%(\mathrm{v} / \mathrm{v})$ serum nutrient broth. The coloniat appearance was observed after 24 and 48 hours' growth at $37^{\circ} \mathrm{C}$ on $5 \%(\mathrm{v} / \mathrm{v})$ blood nutrient agar. Growth at $5^{\circ} \mathrm{C}, 22^{\circ} \mathrm{C}$, and $42^{\circ} \mathrm{C}$ was tested for on blood agar and anaerobic growth on blood agar at $\overrightarrow{0}$ $37^{\circ} \mathrm{C}$ in an atmosphere of $90 \%(\mathrm{v} / \mathrm{v})$ hydrogen afgd $10 \%(\mathrm{v} / \mathrm{v})$ carbon dioxide.

The strains were tested for growth on nutrie agar, on MacConkey agar, on $\mathrm{O} / \mathrm{F}$ medium (Hugh and Leifson, 1953), solidified with $1 \%$ agar, and in

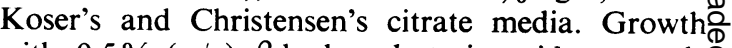
with $0.5 \%(\mathrm{w} / \mathrm{v}) \beta$-hydroxybutyric acid as a sole carbon source was detected on the basal medium of $\overrightarrow{\overrightarrow{0}}$ Owens and Keddie (1968). If growth was ohtained, the bacteria were stained with Sudan Black B to test for the presence of poly- $\beta$-hydroxybutyrate inclusion granules. Those strains failing to grow on this medium were grown on $10 \%(\mathrm{v} / \mathrm{v})$ serum nutrient:agar containing $\beta$-hydroxybutyric acid and then 3 . stained as above. The effect of the following sub-i stances or additives on growth was recorded: $10 \%$ $(\mathrm{v} / \mathrm{v})$ serum in nutrient agar; brilliant green in-을 corporated in blood agar at a concentration of 1 in $500,000(\mathrm{w} / \mathrm{v})$; ox bile in concentrations of $10 \%$ 을. $(\mathrm{w} / \mathrm{v})$ and $40 \%(\mathrm{w} / \mathrm{v})$ and sodium taurocholate in concentrations of $0.5 \%(\mathrm{w} / \mathrm{v})$ and $2 \%(\mathrm{w} / \mathrm{v})$ in- $/$ corporated as ditches in blood agar plates. The N strains of $M$. phenylpyruvica were also tested for $\mathrm{C}_{\mathrm{W}}$ stimulation of growth by stearate, oleate, Tween 80 , 0 butyrate, propionate, valerate, acetate, pelargonate, and lecithin, each at a concentration of $0.1 \%(w / v)$ in blood agar.

Minimum inhibitory concentrations (MICs) of penicillin were determined by subculture on blood agar containing the antibiotic in a range of concen- 
trations between 0.0001 and $100 \mathrm{IU} / \mathrm{ml}$. The Oxford strain of Staphylococcus aureus (NCTC 6571) was used as a control and was inhibited at a concentration of $0.05 \mathrm{IU}$ penicillin $/ \mathrm{ml}$. Tests for the production of penicillinase were made by the method of Parker and Lapage (1957), using two strains of Staphylococcus aureus as controls (NCTC 4136, positive control and NCTC 10443, negative control).

Acid production from glucose was recorded in the $\mathrm{O} / \mathrm{F}$ medium of Hugh and Leifson (1953), both with and without the addition of $10 \%(\mathrm{v} / \mathrm{v})$ serum, and also on $10 \%(\mathrm{v} / \mathrm{v})$ serum nutrient agar slopes containing $1 \%(\mathrm{w} / \mathrm{v})$ glucose and $0.01 \%(\mathrm{w} / \mathrm{v})$ phenol red. Catalase production was tested on cultures grown on $10 \%(\mathrm{v} / \mathrm{v})$ serum nutrient agar, and production of oxidase was detected by Kovacs' (1956) method using tetramethyl-p-phenylenediamine on cultures grown on blood agar.

The following characters were determined in media both with and without $10 \%(\mathrm{v} / \mathrm{v})$ serum: nitrate reduction, urease activity (Christensen's method, 1946), opalescence on egg yolk agar, phosphatase production (phenolphthalein phosphate incorporated in nutrient agar), indole production (Kovacs' and Erhlich's reagents), $\beta$-galactosidase (ONPG), and arginine desimidase (Thornley's medium, 1960). Proteolytic activity was demonstrated by the following tests: liquefaction of gelatin in nutrient gelatin stabs both with and without $10 \%(\mathrm{v} / \mathrm{v})$ serum, and on nutrient agar gelatin plates; serum liquefaction on Loeffler's serum slopes; casein digestion on milk agar plates and in purple milk broth. Decarboxylation of arginine, lysine, and ornithine was tested using Møller's medium (1955) and starch hydrolysis using nutrient agar starch plates. Deamination of phenylalanine was tested for by the method of Shaw and Clarke (1955) and also by agitating a heavy suspension of bacteria in $0.4 \%$ DL-phenylalanine at $37^{\circ} \mathrm{C}$ for one hour followed by the addition of $10 \%(\mathrm{w} / \mathrm{v})$ ferric chloride (Snell and Davey, 1971).

\section{SELECTIVE MEDIUM FOR $M$. phenylpyruvica}

For the attempted isolation of $M$. phenylpyruvica from faeces, a selective medium was devised, containing the following constituents expressed as percentages $(w / v)$ of nutrient agar base: potassium tellurite $0.001 \%$ and sodium taurocholate $1 \%$ as selective agents; glucose $1 \%$, neutral red $0.01 \%$.

\section{DNA BASE COMPOSITIONS}

Deoxyribonucleicacid was extracted by the method of Marmur (1961) and base compositions were estimated by the 'melting temperature' (Tm) method of Marmur and Doty (1962). The Tm determinations were made in either saline-phusphate buffer (SP: $0.1 \mathrm{M} \mathrm{NaCl}+0.01 \mathrm{M}$ phosphate, $p \mathrm{H} \mathrm{7.0)}$ or standard saline-citrate buffer (SSC: $0 \cdot 15 \mathrm{M} \mathrm{NaCl}+$ $0.015 \mathrm{M}$ sodium citrate, $p \mathrm{H} \mathrm{7.0)}$. The equations relating $\mathrm{Tm}$ to the percentage of guanine + cytosine/ total bases $(\% \mathrm{GC})$ for these two buffers were: for SP buffer: $\%$ GC $=2.352 \mathrm{Tm}-153.49$ (Owen, Hill, and Lapage, 1969), and for SSC buffer: \% GC = 2.44 Tm-169.0 (Marmur and Doty, 1962).

\section{Results}

Microscopically, the 11 strains of $M$. phenylpyruvica consisted of non-motile ovals and rods, measuring $0.7 \mu \times 1.5-2.0 \mu$, which were Gram negative, although all strains showed some cells which retained the crystal violet dye as intracellular granules. After overnight incubation, the strains formed convex, translucent colonies on blood agar, about $0.5 \mathrm{~mm}$ in diameter, which enlarged to $1.0 \mathrm{~mm}$ diameter after 48 hours. The colonies were butyrous in consistency and were easily emulsified in saline. No haemolysis was observed on $5 \%$ blood agar but a green discolouration of the blood was noticed around the mass growth of cultures incubated anaerobically. The strains grew at $22^{\circ} \mathrm{C}, 30^{\circ} \mathrm{C}$, and $37^{\circ} \mathrm{C}$ after 24 hours' incubation, at $5^{\circ} \mathrm{C}$ after five days' incubation, and eight of the strains grew at $42^{\circ} \mathrm{C}$ after 48 hours' incubation. All the strains grew anaerobically, although growth was slight with some strains. Growth was obtained on nutrient agar and was improved by the addition of $10 \%$ serum.

The biochemical characters of M. phenylpyruvica, summarized in Table III, agree in general with those described by Bøvre and Henriksen (1967) except for the four tests discussed below:

\section{ANAEROBIC GROWTH}

All strains in the present series showed varying degrees of anaerobic growth, ie, in a hydrogen + carbon dioxide atmosphere, whereas Bøvre and Henriksen (1967) described their strains as failing to grow anaerobically. Possibly this discrepancy is due to different test conditions.

\section{GROWTH ON SOLID O/F MEDIUM}

Bøvre and Henriksen (1967) reported that their strains of $M$. phenylpyruvica grew on this medium. In the NCTC, growth was either poor or absent and the results were not reproducible. This may have been due to differences in inoculum size and carry over of nutrients from the medium on which the bacteria were first grown. Serial subculture of the strains on the $\mathrm{O} / \mathrm{F}$ medium failed to improve the reliability of this test. 


\begin{tabular}{|c|c|c|c|c|}
\hline \multirow[t]{2}{*}{ Tests Positive } & \multirow[t]{2}{*}{ Tests Negative } & \multicolumn{3}{|l|}{ Tests Variable } \\
\hline & & & Positive & Negative \\
\hline Catalase production & Haemolysis & Nitrate reduction & 10 & 1 \\
\hline Oxidase production & Casein digestion & Urease production & 9 & 2 \\
\hline Phenylalanine deamination & Serum liquefaction & Opalescence on egg yolk & 8 & 3 \\
\hline Growth on MacConkey's agar & Gelatin liquefaction & Growth $42^{\circ} \mathrm{C}$ & 8 & 3 \\
\hline Growth stimulated by bile $(10 \%)$ & $\begin{array}{l}\text { Growth on } \beta \text {-hydroxybutyrate } \\
\text { (basal medium) }\end{array}$ & & & \\
\hline Resistance to brilliant green $(1 / 500000)$ & $\begin{array}{l}\text { Poly- } \beta \text {-hydroxybutyrate inclusion } \\
\text { granules (serum agar medium) }\end{array}$ & & & \\
\hline Retention of crystal violet (Gram) by some cells & Citrate utilization & & & \\
\hline Growth $5^{\circ} \mathrm{C}$ & Indole & & & \\
\hline & Acid from glucose & & & \\
\hline & Arginine desimidase & & & \\
\hline & Lysine decarboxylase & & & \\
\hline & Ornithine decarboxylase & & & \\
\hline & $\beta$-galactosidase (ONPG) & & & \\
\hline & Starch hydrolysis & & & \\
\hline & Phosphatase production & & & \\
\hline
\end{tabular}

Table III Biochemical characters of Moraxella phenylpyruvica

\section{PENICILLIN SENSITIVITY}

Bøvre and Henriksen (1967) reported MICs to range from 0.0005 to 0.04 IU penicillin $/ \mathrm{ml}$ for their $M$. phenylpyruvica strains. They calculated MICs from inhibition zone diameters and regression equations. With our different technique (see Bacteriological Investigations), eight of our strains were inhibited within a range of 0.05 to 0.5 IU penicillin $/ \mathrm{ml}$ incorporated in the agar. Three strains grew in the presence of $100 \mathrm{IU}$ penicillin $/ \mathrm{ml}$ and were subsequently found to produce penicillinase. The MICs of the strains are given in Table IV.

\begin{tabular}{lc}
\hline Strain & MICs $(I U m l)$ \\
\hline NCTC 10752 & $0 \cdot 05$ \\
3 & $0 \cdot 10$ \\
$1,2,4,8$ and NCTC 10526, 10750 & $0 \cdot 50$ \\
$5,6,7$ (penicillinase positive) & $>100$
\end{tabular}

Table IV Minimum inhibitory concentrations (MICs) of penicillin for $\mathrm{M}$. phenylpyruvica

4 DEAMINATION OF PHENYLALANINE All the strains of $M$. phenylpyruvica produced phenylpyruvic acid from phenylalanine both by the sensitive agitation method of Snell and Davey (1971) and in the medium of Shaw and Clarke (1955). In this latter medium, hower, incubation for 48 hours was required before a colour reaction could be observed, which was often faint but usually stronger if the medium was enriched with serum. Bøvre and Henriksen (1967) found that deamination of phenylalanine was restricted to M.phenylpyruvica, but, in the present study, several strains of some other Moraxella spp were also found to deaminate phenylalanine when tested by the 'agitation' method (see Table V).

\begin{tabular}{|c|c|c|}
\hline Species & Positive Strains & Negative Strains \\
\hline M. osloensis & 10749,10756 & 10465,10755 \\
\hline M. lacunata & - & $7985,10747,10748$ \\
\hline M. saccharolytica & 10753 & - \\
\hline M. kingii & - & 10529,10746 \\
\hline$M$. sp. (Van Bijsterveld) & 10717 & - \\
\hline M. bovis & 一 & $\begin{array}{l}8561,9425,9426 \\
\text { A52/69 }\end{array}$ \\
\hline M. liquefaciens & 10358,10359 & 7911 \\
\hline M. nonliquefaciens & - & $\begin{array}{l}7784,10464 \\
\text { A33/67, A9/69 }\end{array}$ \\
\hline
\end{tabular}

Table V Deamination of phenylalanine by Moraxella spp. other than M. phenylpyruvica as determined by the. method of Snell and Davey (1971)

STIMULATION OF GROWTH BY BILE The growth of strains of $M$. phenylpyruvica was found to be improved on MacConkey agar. Ox bile and unpurified sodium taurocholate were then found to stimulate growth, while strains of other Moraxella spp were unaffected or inhibited by these sub-? stances. The stimulation of $M$. phenylpyruvica was presumably due to impurities known to be present in bile salts (Leifson, 1935; Society for General $\frac{0}{2}$ Microbiology, 1956), because Analar grade sodium taurocholate did not exert a stimulatory effect.

Fatty acids are likely to be present in bile salts and have variable effects on bacterial growth (Leifson, 1935; Wildy and Hare, 1953). Baumann, Doudoroff, N and Stanier (1968) found that oleic acid stimulated some strains of $M$. lacunata. In the present study, $\mathcal{N}$ growth of $M$. phenylpyruvica was stimulated by $\tilde{\omega}^{N}$ stearate, oleate, and Tween 80 , but not by butyrate, 0 propionate, valerate, acetate, pelargonate, or leci-o thin.

DNA BASE COMPOSITIONS

The DNA base compositions determined in the 
present study, and previously published data for the same strains, are expressed as the percentage of guanine and cytosine/total bases present ( $\%$ GC) and are given in Table VI. The values found for $M$. phenylpyruvica, NCTC $10526(42 \cdot 2 \%$ GC) and $M$. sp. NCTC $10717(48.0 \%$ GC) closely agree with those given by Bøvre and Henriksen (1967) and van Bijsterveld (1970), who made their determinations from buoyant densities (Schildkraut, Marmur, and Doty, 1962). The previous discrepancy between the value of $49.0 \%$ GC for $M$. kingii NCTC 10529 (Hill, Snell, and Lapage, 1970) and $44.5 \%$ GC (Bøvre, Fiandt, and Szybalski, 1969) was checked again with a fresh preparation which gave $48.7 \%$ GC. Discrepancies between laboratories are not uncommon (Hill, Leach, and Andrews, 1970), though not usually as large as this.

\section{DISTRIBUTION OF $M$. phenylpyruvica STRAINS}

The conjunctiva, skin, and mucous membranes are usually considered to be the natural habitat of
Moraxella spp. M. phenylpyruvica has been isolated, however, from the urogenital tract, blood cultures, cerebrospinal fluid, and pus from various lesions (Flamm, 1957; Bøvre and Henriksen, 1967; Pedersen, Marso, and Pickett, 1970), and from pleural fluid, nasal swabs, and pressure sores (this paper). Some of these sites are liable to faecal contamination. Faeces have not been previously considered as a possible reservoir of this species which, moreover, is stimulated by bile. This possibility was therefore investigated.

The selective medium devised was successful for the recovery of all strains of $M$. phenylpyruvica added to faeces. The selective agents inhibited the majority of the faecal flora except some streptococci. The colonies of $\boldsymbol{M}$. phenylpyruvica on this medium were colourless, whereas other organisms produced acid from the glucose and thus formed red colonies. One hundred specimens of faeces from different patients were cultured on this medium, but no strains of M. phenylpyruvica were found.

\begin{tabular}{|c|c|c|c|c|}
\hline \multicolumn{2}{|c|}{ NCTC Numbers and Names } & \multirow{2}{*}{$\begin{array}{l}\text { Percentage GC (Present Study) } \\
\text { from Melting Temperatures }\end{array}$} & \multicolumn{2}{|c|}{ Percentage GC (Other Published Data) from } \\
\hline & & & Melting Temperatures & Buoyant Densities \\
\hline $\begin{array}{l}10526 \\
10717 \\
10529 \\
10753\end{array}$ & $\begin{array}{l}\text { M. phenylpyruvica } \\
\text { M. sp. (Van Bijsterveld) } \\
\text { M. kingii } \\
\text { M. saccharolytica }\end{array}$ & $\begin{array}{l}42 \cdot 2 \\
48 \cdot 0 \\
48 \cdot 7 \\
38 \cdot 4\end{array}$ & $\begin{array}{l}- \\
49 \cdot 0^{3}\end{array}$ & $\begin{array}{l}43 \cdot 0^{1} \\
49 \cdot 0^{2} \\
44 \cdot 5^{4} \\
-\end{array}$ \\
\hline
\end{tabular}

Table VI DNA base compositions determined in the present work

\begin{tabular}{|c|c|c|c|c|c|c|c|c|c|}
\hline & $\begin{array}{l}\text { Moraxella } \\
\text { phenyl- } \\
\text { pyruvica }\end{array}$ & $\begin{array}{l}\text { M. oslo- } \\
\text { ensis }\end{array}$ & $\begin{array}{l}\text { M. lacu- } \\
\text { nata }\end{array}$ & $\begin{array}{l}\text { M. sac- } \\
\text { charo- } \\
\text { lytica }\end{array}$ & M. kingii & $\begin{array}{l}\text { M. sp. } \\
\text { (Val } \\
\text { Bijster- } \\
\text { veld })\end{array}$ & M. bov & $\begin{array}{l}\text { is } M . \\
\text { lique- } \\
\text { faciens }\end{array}$ & $\begin{array}{l}\text { M. non- } \\
\text { lique- } \\
\text { faciens }\end{array}$ \\
\hline Number of strains & 11 & 4 & 3 & 1 & 2 & 1 & 4 & 3 & 4 \\
\hline Catalase & + & + & + & + & - & + & $\div$ & + & + \\
\hline Growth on MacConkey agar & + & + & - & - & - & - & - & 2 & - \\
\hline Phenylalanine deamination (agitation method) & + & 2 & - & + & - & $\div$ & - & 2 & - \\
\hline Nitrate reduction & 10 & 2 & 2 & + & - & - & - & + & + \\
\hline Retention of crystal violet (Gram) & + & 2 & 1 & - & - & - & - & 2 & - \\
\hline Urease & 9 & - & - & - & - & - & - & - & - \\
\hline Opalescence on egg yolk & 8 & - & - & - & - & - & 3 & + & - \\
\hline Growth stimulation by bile & + & - & - & - & - & - & - & - & - \\
\hline Casein digestion & - & - & + & - & \pm & \pm & + & + & - \\
\hline Serum liquefaction & - & - & + & - & - & - & $\div$ & + & - \\
\hline Resistance to brilliant green $1 / 500000$ & + & 2 & - & - & - & - & 1 & + & - \\
\hline Phosphatase & - & 1 & 1 & + & + & + & - & - & - \\
\hline Poly- $\beta$-hydroxybutyrate granules & - & + & - & - & - & - & - & - & - \\
\hline Hacmolysis & - & - & - & - & + & - & + & - & - \\
\hline Acid from glucose & - & - & - & + & + & + & - & - & - \\
\hline Growth $5^{\circ} \mathrm{C}$ & + & - & - & - & - & - & - & - & - \\
\hline Growth $42^{\circ} \mathrm{C}$ & 8 & - & - & - & - & - & - & - & - \\
\hline DNA base composition, $\%$ GC (selected strains) & $42-43 \cdot 5^{1}$ & $43 \cdot 5^{2}$ & $42^{2}$ & $38 \cdot 3$ & $49 \cdot 04$ & $48-49^{3}$ & $42 \cdot 5^{8}$ & $41 \cdot 5^{2}$ & $42 \cdot 2^{2}$ \\
\hline
\end{tabular}

Table VII Differentiation of Moraxella phenylpyruvica

${ }^{1}$ Bøvre and Henriksen (1967), Bøvre, Fiandt, and Szybalski (1969), and Table VI 'Bøvre, Fiandt, and Szybalski (1969).
'Van Bijsterveld (1970), and Table VI. ‘Hill, Snell, and Lapage (1970), and Table VI. 


\section{Discussion}

The eight field strains and three NCTC strains of Moraxella phenylpyruvica form a homogeneous group differing from other Moraxella spp in a number of characters (see Table VII). Although deamination of phenylalanine is not limited to $M$. phenylpyruvica, nonetheless this species can be readily distinguished; in particular, it is urease positive (nine of 11 strains), stimulated by bile and grows at $5^{\circ} \mathrm{C}$, which are features not shown by other moraxellas. Considered in pairs, $M$. phenylpyruvica differs from each of the other Moraxella spp in Table VII in six (M. osloensis, M. liquefaciens) to 14 characters ( $M$. kingii).

The DNA base composition of $M$. phenylpyruvica $(42 \cdot 0-43 \cdot 5 \%$ GC) lies within the range of base compositions of other nonsaccharolytic moraxellas $(41 \cdot 5-43 \cdot 5 \%$ GC, see Table VII). Saccharolytic moraxellas lie slightly outside this range: $M$. kingii and $M$. sp. NCTC 10717 have higher values (48-49\% GC) and $M$. saccharolytica a lower value (38.5\% GC). The saccharolytic moraxellas should perhaps be excluded from the genus Moraxella; Henriksen and Bøvre (1968), in fact, considered $M$. kingii to be only 'distantly related' to other Moraxella spp, but saw no other alternative genus for its inclusion.

Bøvre and Henriksen (1967) and Bøvre (1970) found no genetic transformation between $M$. phenylpyruvica and $M$. nonliquefaciens, and only low similarity in DNA-RNA in vitro molecular hybridization experiments, despite the similarity in base composition. $M$. nonliquefaciens, on the other hand, had varying degrees of compatibility in transformation experiments with other Moraxella spp.: M. bovis $M$. lacunata, $M$. liquefaciens, and $M$. osloensis. $M$. phenylpyruvica thus appear to be genetically isolated. The taxonomic utility of DNA base composition is limited to where there are differences in composition, indicating dissimilarity in base sequences, ie, genetic messages, which, in turn, indicate unrelatedness. The contrary finding of a similar base composition does not necessarily imply similar base sequences. The genetic evidence above and the low phenetic similarity with other Moraxella spp. suggests that $M$. phenylpyruvica is only distantly related to other members of the genus.

Baumann et al (1968) amended the definition of the genus Moraxella to include sensitivity to 1 IU penicillin $/ \mathrm{ml}$, although the moraxellas they studied did not include saccharolytic strains. The discovery of three strains of $M$. phenylpyruvica producing penicillinase and growing in the presence of $100 \mathrm{IU}$ penicillin $/ \mathrm{ml}$ shows that the criterion of penicillin sensitivity for inclusion in the genus Moraxella should not be applied in a monothetic fashion (Sokal and Sneath, 1963).

The pathogenicity of $M$. phenylpyruvica is $\stackrel{0}{*}$ probably low, although it may possibly be an 을 opportunist pathogen. It is difficult to assign a $\overrightarrow{\vec{F}}$ causative role of the clinical conditions to infection $\stackrel{5}{+}$ by any of the strains described here. However, two strains of this organism were isolated from blood cultures by the late Dr E. O. King ( fide Bøvre and $\frac{\sigma}{\widehat{\sigma}}$ Henriksen, 1967) and Flamm's original strain was $\varrho$ from cerebrospinal fluid in a case of infant menin- $ڤ$ gitis. Despite our failure to demonstrate the presence $\overrightarrow{0}$ of $M$. phenylpyruvica in faeces, it remains a possibility that this organism is present in the intestinal $\vec{\omega}$ tract but only in small numbers in faeces or else that $\frac{\Omega}{2}$ the carrier rate is low. Examination of faeces from 0 patients with infections due to $M$. phenylpyruvica of would be interesting and might be more successful. $\vec{\overrightarrow{ }}$ It would be useful to devise an enrichment medium, io although it might prove difficult as these bacteria of grow poorly in liquid media. Many bacteria grow in $\frac{\circ}{2}$ the presence of bile, but stimulation is rare. Stimu- lation of Bacteroides fragilis by bile has been reported $Z$ (Loesche, Socransky, and Gibbons, 1964).

Reports of the isolation of $M$. phenylpyruvica are rare, but the isolation of eight strains in the UK over $\underset{\Phi}{\mathscr{\Phi}}$ a period of three years indicates that this species may be more widely distributed than the paucity $f$ reports would suggest. The relative ease of identif $N$ cation, using the characteristics described in th paper, may lead to the identification of furth strains.

We wish to thank Drs R. F. Alexander, J. C. Burne, E. G. Gordon, M. P. Jevons, I. R. Poulter, W. E. Rimington, and K. B. Rogers for sending us their 3 strains and for the clinical details of their cases, and Dr S. D. Henriksen for initial identification of strain 2 as $M$. phenylpyruvica.

References

Baumann, P., Doudoroff, M., and Stanier, R. Y. (1968). Study of the Moraxella group. I. Genus Moraxella and the Neisseria catarrhalis group. J. Bact., 95, 58-73.

Bøvre, K. (1970). Pulse-RNA-DNA hybridization between rodshaped and coccal species of the Moraxella-Neisseria groups. Acta $D$ path. microbiol. scand., Sect. B, 78, 565-574.

Bøvre, K., Fiandt, M., and Szybalski, W. (1969). DNA base composition of Neisseria, Moraxella, and Acinetobacter, as deter- N mined by measurement of buoyant density in $\mathrm{CsCl}$ gradients. Canad. J. Microbiol., 15, 335-338.

Bøvre, K., and Henriksen, S. D. (1967). A revised description of Moraxella polymorpha Flamm 1957, with a proposal of a new $\mathcal{W}$ name, Moraxella phenylpyrouvica for this species. Int. J. syst. $\sigma$ Bact., 17, 343-360.

Christensen, W. B. (1946). Urea decomposition as a means of differentiating Proteus and paracolon cultures from each other $\frac{\subset}{(\Phi)}$ and from Salmonella and Shigella types. J. Bact., 52, 461-466. \&

Cowan, S. T., and Steel, K. J. (1965). Manual for the Identification of ${ }^{+}$ Medical Bacteria. University Press, Cambridge.

De Bord, G. G. (1939). Organisms invalidating the diagnosis of $\bar{O}$ gonorrhea by the smear method. (Abstr.) J. Bact., 38, 119-120. 
De Bord, G. G. (1942). Descriptions of Mimeae trib. nov. with three genera and three species and two new species of Neisseria from conjunctivitis and vaginitis. Iowa State Coll. J. Sci., 16, 471480. (Cited by Bøvre and Henriksen, 1967.)

Flamm, H. (1956). Moraxella saccharolytica (sp. n.) aus dem Liquor eines Kindes mit Meningitis. Zbl. Bakt., I. Abt. Orig., 166, 498-502.

Flamm, H. (1957). Eine weitere neue Species des Genus Moraxella M. polymorpha sp. n.more Zbl.|Bakt., I. Abt. Orig., 168, 261-267.

Henriksen S. D., and Bøvre, K. (1968). Moraxella kingii sp. nov., a haemolytic saccharolytic, species of the genus Moraxella. J. gen. Microbiol., 51, 377-385.

Hill, L. R., Leach, R. H., and Andrews, B. E. (1970). The value of DNA base composition determinations in the classification of some atypical mycoplasmas. Spisy prir. Fak. Univ. Brne, 47, Ser. $K$., p. 79-83.

Hill, L. R., Snell, J. J. S., and Lapage, S. P. (1970). Identification and characterisation of Bacteroides corrodens. J. med. Microbiol., 3, 483-491.

Hugh, R., and Leifson, E. (1953). The taxonomic significance of fermentative versus oxidative metabolism of carbohydrates by various gramnegative bacteria. J. Bact., 66, 24-26.

Judicial Commission of the International Committee on Systemic Bacteriology (1971). Opinion 42. Conservation of the specific epithet 'phenylpyruvica' in the name Moraxella phenylpyruvica. Bøvre and Henriksen Int. J. syst. Bact., 21, 107.

Kovacs, N. (1956). Identification of Pseudomonas pyocyanea by the oxidase reaction. Nature (London), 178, 703.

Leifson, E. (1935). New culture media based on sodium desoxycholate for the isolation of intestinal pathogens and for the enumeration of colon bacilli in milk and water. J. Path. Bact., 40, 581-599.

Loesche, W. J., Socransky, S. S., and Gibbons, R. J. (1964). Bacteroides oralis, proposed new species isolated from the oral cavity in man. J. Bact., 88, 1329-1337.

Marmur, J. (1961). A procedure for the isolation of deoxyribonucleic acid from microorganisms. J. molec. Biol., 3, 208-218.

Marmur, J., and Doty, P. (1962). Determination of the base composition of deoxyribonucleic acid from its thermal denaturation temperature. J. molec. Biol., 5, 109-118.
Meller, V. (1955). Simplified tests for some amino acid decarboxylases and for the arginine dihydrolase system. Acta path. microbiol. scand., 36, 158-172.

Owen, R. J., Hill, L. R., and Lapage, S. P. (1969). Determination of DNA base compositions from melting profiles in dilute buffers. Biopolymers, 7, 503-516.

Owens, J. D., and Keddie, R. M. (1968). A note on the vitamin requirements of some coryneform bacteria from soil and herbage. J. appl. Bact., 31, 344-348.

Parker, M. T., and Lapage, S. P. (1957). Penicillinase production by Staphylococcus aureus strains from outbreaks of food poisoning. J. clin. Path., 10, 313-317.

Pedersen, M. M., Marso, E., and Pickett, M. J. (1970). Nonfermentative bacilli associated with man: III. Pathogenicity and antibiotic susceptibility. Amer. J. clin. Path., 54, 178-192.

Schildkraut, C. L., Marmur, J., and Doty, P. (1962). Determination of the base composition of deoxyribonucleic acid from its buoyant density in $\mathrm{CsCl}$. J. molec. Biol., 4, 430-443.

Shaw, C., and Clarke, P. H. (1955). Biochemical classification of Proteus and Providence cultures.J. gen. Microbiol., 13, 155-161.

Snell, J. J. S., and Davey, P. (1971). A comparison of methods for the detection of phenylalanine deamination by Moraxella species. J. gen. Microbiol., 66, 371-73.

Society for General Microbiology (1956). Constituents of Bacteriological Culture Media: Special Report, edited by G. Sykes, pp. 30-33. University Press, Cambridge.

Sokal, R. R., and Sneath, P. H. A. (1963). Principles of Numerical Taxonomy. Freeman, San Francisco and London.

Thornley, M. J. (1960). The differentiation of Pseudomonas from other Gram-negative bacteria on the basis of arginine metabolism. J. appl. Bact., 23, 37-52.

van Bijsterveld, O. P. (1970). New Moraxella strain isolated from angular conjunctivitis. Appl. Microbiol., 20, 405-408.

van Bijsterveld, O. P. (1971). Bacterial proteases in Moraxella angular conjunctivitis. Amer. J. Ophthul., 72, 181-184.

Wildy, P., and Hare, R. (1953). The effect of fatty acids on the growth, metabolism and morphology of the anaerobic cocci. J. gen Microbiol., 9, 216-225. 